\title{
The Investigation of Alpha-Tubulin Differential Expression in Oligodendroglioma Brain Tumor Aiming MALDI-TOF-TOF
}

\author{
Mehdi Pooladi ${ }^{1 * \infty}$, Mehrdad Hashemi², Saeed Hesami Tackallou ${ }^{3 \oplus}$, Soheila Karani ${ }^{1^{(}}$ \\ 'Department of Biology, School of Basic Sciences, Science and Research Branch, Islamic Azad University, Tehran, Iran \\ ${ }^{2}$ Department of Molecular Genetics, Tehran Medical Branch, Islamic Azad University, Tehran, Iran \\ ${ }^{3}$ Department of Biology, Central Tehran Branch, Islamic Azad University, Tehran, Iran
}

\begin{abstract}
Background: Tubulin is known as a heterodimer protein, which includes alpha and beta tubulin subunits. This structural protein plays important roles in pathogenesis and healing different diseases. Biomarkers help in fast and accurate detection of cancer. Proteomic studies can be useful both in biological and clinical research, also help obtain protein expression profiles by using twodimensional electrophoresis, mass spectrometry, and bioinformatics tools. Finding candidate proteins as cancer biomarkers is an interesting area in proteomic investigations.

Methods: In the present study, the total protein content of healthy cells of the brain and brain tumor cells were extracted, purified and quantified by Bradford assay. Two-dimensional electrophoresis used for protein separation followed by statistical analysis. Primary protein detection was performed based on the differences in isoelectric $\mathrm{pH}$, the molecular weight of proteins and protein data banks, which was further confirmed by Matrix Assisted Laser Desorption Ionisation-Time-of-Flight (MALDITOF-TOF).

Results: In this study, an alpha-tubulin expression found changed (overexpression) in Oligodendroglioma tumors comparing control identified by proteomics analysis. Also, alphatubulin position showed in the oligodendroglioma tumors cluster diagram.

Conclusion: Proteome analysis approach has allowed biology and medical studies. Alpha-tubulin introduced as a candidate biomarker for the diagnosis and prediction of oligodendroglioma tumors. Keywords: Alpha-Tubulin; Oligodendroglioma; MALDI-TOF-TOF; Proteomics.
\end{abstract}

*Correspondence to Mehdi Pooladi, Department of Biology, School of Basic Sciences, Science and Research Branch, Islamic Azad University, Tehran, Iran. Tel: (+98) 9173074007 Email: Mehdi.pooladi7@gmail. com

Published online 29 June 2019

Citation: Pooladi M, Hashemi M, Hesami Tackallou S, Karani S. The investigation of alpha-tubulin differential expression in oligodendroglioma brain tumor aiming MALDI-TOF-TOF. Int Clin Neurosci J. 2019;6(2):53-58. doi:10.15171/icnj.2019.11.

\section{Introduction}

Oligodendroglioma, a subtype of gliomas, account for $4.2 \%$ of all primary brain tumors. ${ }^{1,2}$ Gliomas are the most malignant of human brain tumors, and also the most common type of primary brain tumor..$^{3-6}$ Oligodendroglioma tumors have a high sensitivity to chemotherapy; usually, they respond positively to the treatment. ${ }^{7,8}$ The relevant genes and proteins conveying the favorable clinical effects associated with of $1 p, 19 q$ and oligodendroglioma tumors are still unknown. ${ }^{9-11}$

Tubulin is a heterodimer protein $(100 \mathrm{Da})$, consisting of microtubules (alpha and beta) polypeptide chains. In human, alpha tubulin has 6 subunit genes, and also beta-tubulin has seven subunit genes, that expressed in different types of tissues. ${ }^{12,13}$ However, in the nucleation of microtubules in a eukaryotic cell, $\gamma$-tubulin has a function. $\gamma$-Tubulin is a major protein in eukaryotic cells, that present and effective in centrosome and cytoplasm. ${ }^{14}$ The structure of alpha and beta tubulin is highly dynamic..$^{15,16}$
Microtubules are critically involved in cellular processes, mitosis, intracellular transport, the scheduled cell death (apoptosis), the mechanism of cancer formation, and also cancer treatment (chemotherapy, radiation therapy, and anti-tumor drugs). ${ }^{17,18}$ These microtubules has primary and essential functions in the cytoskeleton and may provide an attachment site for contractile proteins. Microtubules are cytoskeletal hollow fibers present in most eukaryotic cells that have cancer treatment users. Tubulin acetylated in $\varepsilon$ amino, that conserved lys ${ }_{40}{ }^{19-21}$ Previous reports demonstrated, intermediate filament proteins contain motifs (the motifs are short) that causes the connection of non-polymerizes tubules and that peptides include 24 amino acids, the ability and capacity binding to sites maintain tubulin. ${ }^{22}$

The proteomics research deals with systematic analysis of protein profiles of the proteins expressed in given cell, tissue, and biological system at a given time, and then compare the conditions differently. ${ }^{23-25}$ As proven 
in previous research, the proteome contains proteins resulting from the translation of the genome, as well as the proteins resulting from changes after translation. These are the backbone of protein biomarkers. ${ }^{26,27}$ Cancer biomarkers for the early detection of malignancies and choice of appropriate treatment has requested in the different kinds of diseases. ${ }^{28}$ Proteomics has produced types of biomarker candidates for cancer, But this is important, that biomarkers are specific. ${ }^{29-31}$ The $2 \mathrm{DE}$ and MS are suitable methods for proteomics research, which analyzed the proteome of the glioma tissue and standard brain samples. Alteration in expression proteome detected, also showed most changes in expression levels of proteins related to metabolism, cytoskeleton, proteasome, and immune systems. ${ }^{32,33}$ Advanced proteome imaging techniques included isoelectric focusing (IEF) approach, immobilized $\mathrm{pH}$ gradient (IPG) gel, gel trypsin digestion, and then MALDI-TOF-TOF analysis For proteins identification. $^{34,35}$

In this article, we investigated the alpha-tubulin expression change in oligodendroglioma tumor. We extracted proteins and separated proteins using 2DE, analyzed the software, then identified alternation in oligodendroglioma of alpha-tubulin by statistical data, protein databases in proven research and MALDI TOFTOF.

\section{Methods}

\section{Patient Samples}

Tissues were obtained, with informed consent and institutional review board approval, from patients undergoing tumor resection. For this study, all individuals filled a written informed consent form. Oligodendroglioma tumors were surgically removed and then classified [according to the World Health Organization (WHO)] at the hospital. The control tissue obtained from the margin of confidence around the tumor.

\section{Tissue and Sample Preparation}

The following protocol used for protein extraction and preparation of tumor tissue samples: tissue samples were washed with PBS, cell lysis by sonication (samples received 3 rounds of sonication, and each round lasted 30 seconds), acetone (50\% and $100 \%$ ) wash at $4^{\circ} \mathrm{C}, 15000$ $\mathrm{g}$, and three rounds of 30 minutes each. In the following, the obtained pellet kept on $-20^{\circ} \mathrm{C}$ overnight. Protein solubilization following acetone removal by adding $1 \mathrm{ml}$ of rehydration buffer and $50 \mu \mathrm{L}$ of a protease inhibitor to each protein pellet containing tubes. Finally, the Bradford assay used for the analysis of each tissue sample protein content.

\section{Two-Dimensional Gel Electrophoresis}

Two-dimensional gel electrophoresis for protein separation was performed with IPG strips $(18 \mathrm{~cm})$ by IEF.
IPG trips had then transformed to SDS-PAGE gel and proteins were further separated based on their molecular weight. Followed by a final coomassie blue staining of the SDS-PAGE gel.

\section{SDS-PAGE Scan and Bioinformatics analysis}

We used Scanner [densitometer GS-800 (BioRad)] to scan gels. Followed by a primary analysis of $2 \mathrm{D}$ images by Quantity One ${ }^{\circledR}$ software. The obtained scanned images of SDS-PAGE gels has further analyzed by NonLinear Dynamics Progenesis Same Spot ${ }^{\circledR}$ Software. After comparing the obtained 2D images with control samples, first protein detection was performed based on the protein bands.

SDS-PAGE gels were scanned using scanner Densitometer GS-800 (BioRad) scanner at 600 dpi in tagged image file format (TIFF). ImageMaster ${ }^{\mathrm{TM}} 2 \mathrm{D}$ platinum v6.0 software was then used to extract and digitize data from graphical images of scanned gels through detecting, normalizing, matching and comparing protein spots according to their volume percent.

\section{MS Analysis}

MS was used to confirm the early protein detection results obtained by analysis of $2 \mathrm{D}$ image analysis. The identity of differentially expressed proteins was established using MS. The calculation standard in this study is fold more than two.

\section{Statistical Analysis, Clustering, and PCA}

The obtained results were statistically analyzed by $t$ test $(P<0.05)$, and SPSS version 19.

Protein spots with $P<0.05$ divided into 2 groups: increased and decreased protein expression groups. Then, clustering was used to identify the location of significantly significant spots, followed by PCA in determining the accuracy of the obtained results. Cluster analysis performed on two groups.

1. Proteins that have increased expression

2. Protein that has decreased expression

\section{Results}

Electrophoresis and MALDI-TOF-TOF Analysis

We compared protein expression patterns between oligodendroglioma samples relative to control, using 2DGE and MALDI-TOF-TOF proteomics analysis. The 2DE showed 1328 spots. A total of 433 spots showed statistically significant differences in the image, alphatubulin ( 2 spots of total spots) were identified using the data obtained from MS in conjunction with a search of the databank (NCBI, www.ncbi.nlm.nih.gov/protein). MALDI-TOF-TOF results revealed that those two spots represent a total of up-regulated proteins. Among them the statistically significant protein spots alpha-tubulin proteins were definitely with $\mathrm{pH}_{\mathrm{i}}: 4.94$ and MW: $50804 \mathrm{Da}$ detected which has an up-regulation about 3.1 (fold=3.1) 
for the first spot, and (second spot) $\mathrm{pH}_{\mathrm{i}}: 5.02$ and MW: $50810 \mathrm{Da}$ detected which has an up-regulation about 2 (fold=2) for the second spot, in oligodendroglioma tumors than control (Figure 1). Comparison of spot alpha tubulin between healthy tissue and tumor differentially expressed spot in oligodendroglioma tumor (Figure 2).

In this experiment, we saw changes in alpha-tubulin expression (up-regulated) in oligodendroglioma tumor than control identified by MALDI-TOF-TOF. Levels of alpha-tubulin spots were markedly higher in oligodendroglioma than non-tumor. We analyzed data from the MALDI-TOF-TOF, were shown in Table 1. Also, the position of the peptide presented has shown in Figure 3. Then, peptides that match the information in the databank searching obtained as shown in Table 2.

\section{Spots Clustering}

Spots statistical analysis have commonly used nonlinear Progenesis Samespots software in which the change in protein levels. Accordingly, proteins has classified into 2

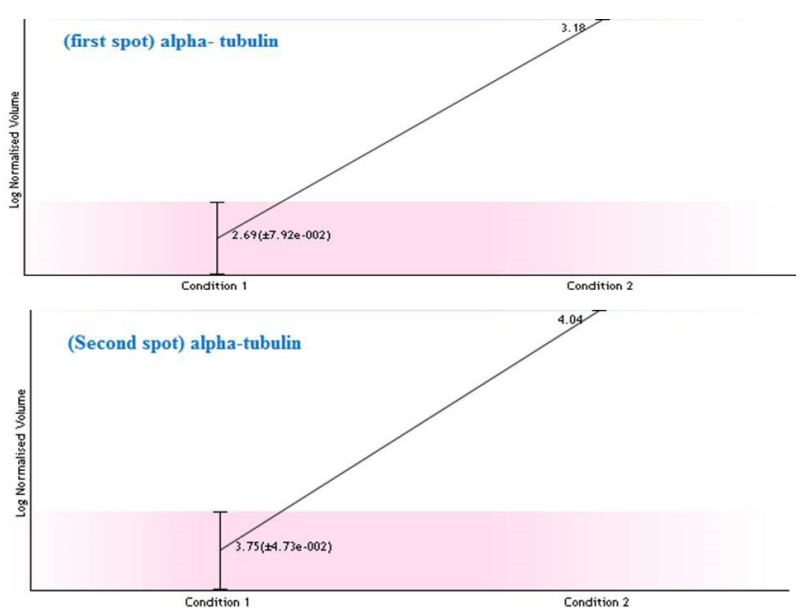

Figure 1. (First spot) alpha-tubulin protein has an up-regulation about 3.1 (fold=3.1) in oligodendroglioma brain tumor than normal brain tissue. (Second spot) alpha-tubulin protein has an up-regulation about 2 ( $f \circ l d=2$ ) in oligodendroglioma brain tumor than normal brain tissue. categories: proteins that have increased expression and proteins that have reduced expression. Alpha-tubulin identified by MALDI-TOF-TOF, then it was identified in the expression increased group (red), alpha tubulin position in the clustering was determined by isoelectric $\mathrm{pH}$ and molecular weight. We have identifand alphatubulin position and was shown in Figure 4.

For more understanding about rates of change, each of the tumors has compared with the controls. $\mathrm{MW}$ and $\mathrm{pH}_{\mathrm{i}}$ values recorded in Table 3 . Then, statistical analysis has shown in Table 4.

\section{Discussion}

Proteomics and proteome analysis approach have allowed biology and medical studies of protein expression for different goals in different tissues, serum, CSF, urine and all biological fluids in despite conditions and types of Time. ${ }^{36,37}$ For more understanding, the protein molecular mechanisms involved in rabies pathogenesis different proteomics approach has used including proteome analysis of several in vitro, and in vivo host models infected with

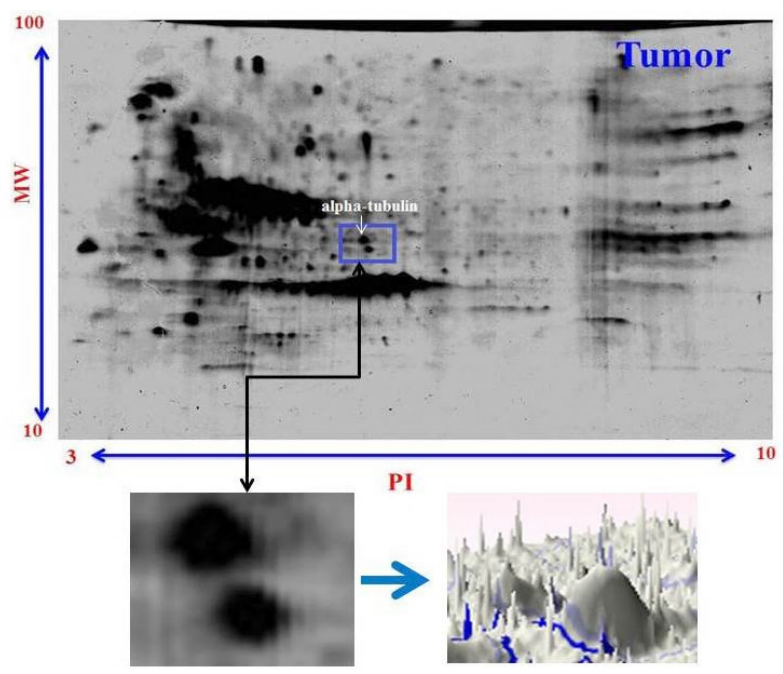

Figure 2. 3D Images of Alpha-Tubulin Protein in Oligodendroglioma Tumor Tissue.

Table 1. Analyzed Data by MALDI-TOF-TOF for Alpha-Tubulin in Oligodendroglioma Tumor Than Control

\begin{tabular}{|c|c|c|c|c|c|c|}
\hline gi340021 & Observed & $M r($ expt) & Mr (calc) & PPM & Score & Expect \\
\hline \multirow[t]{8}{*}{ gi340021 } & 1023.4638 & 1022.4565 & 1022.4417 & 14.5 & 58 & 0.0013 \\
\hline & 1085.6414 & 1084.6341 & 1084.6128 & 19.6 & 69 & $8.6 e-05$ \\
\hline & 1410.8043 & 1409.7970 & 1409.7667 & 21.5 & 96 & $1.9 \mathrm{e}-07$ \\
\hline & 1487.9089 & 1486.9017 & 1486.8719 & 20.0 & 93 & $2.4 \mathrm{e}-07$ \\
\hline & 1701.9344 & 1700.9272 & 1700.8985 & 16.8 & 119 & 7.6e-10 \\
\hline & 1718.9132 & 1717.9059 & 1717.8747 & 18.2 & 60 & 0.00072 \\
\hline & 1756.9852 & 1755.9780 & 1755.9559 & 12.5 & 121 & $5 e-10$ \\
\hline & 2409.1929 & 2408.1856 & 2408.2012 & -6.49 & 185 & $1.7 \mathrm{e}-16$ \\
\hline gi37492 & 1457.8995 & 1456.8923 & 1456.8613 & 21.2 & 81 & $3 e-06$ \\
\hline
\end{tabular}




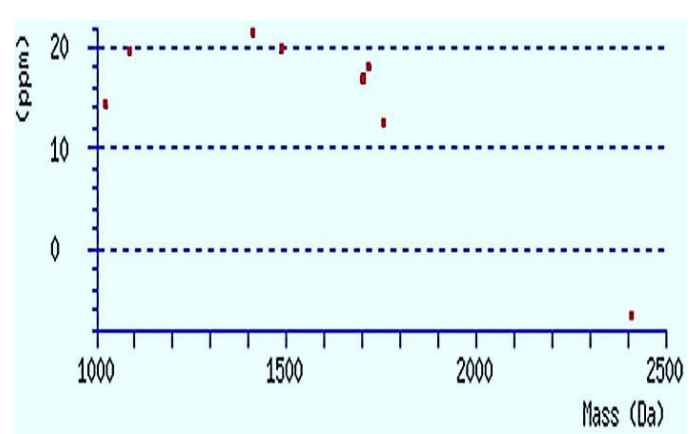

Figure 3. MALDI-TOF-TOF showed the position of the peptide for alphatubulin in oligodendroglioma tumor.

different cancer related to protein, for example, dynamic alterations, phosphorylation, trafficking and localization, and protein-protein interactions. Phosphorylation and nuclear localization of protein cells involved in cancer may be clinical potential cancer biomarkers. ${ }^{28,38}$ Actually, changes after translation such as acetylation and phosphorylation for tubulin is affecting the variety of diseases. These changes can be useful in diseases of the nervous system and neurodegenerative diseases. The acetylation of a tubulin plays an essential role in regulating stability and structure microtubule, specific tubulin function such as can division and intracellular trafficking. ${ }^{39,40}$ The protein dynamic structures because of the interaction of alpha and beta tubulins polymers with associated microtubule. Microtubule has different functions in cells, such as cell motility, maintenance of cell shape, mitosis, and organization. ${ }^{41,42}$

Changes made to the amino acids cause may Cause the decrease of a specific contact with an interesting molecule. ${ }^{43,44}$ The desire to change of a protein molecule or a lipid molecule depends on its basic structure and modifications of the peptide resulting from the sequence modification. ${ }^{45}$ It is necessary to remember that small peptides line neurofilament (NFL) lightweight (about $61 \mathrm{kDa}$ ) tubulin binding sites. For example, the basic structure of tubulin is not known in complete detail, but protein baby related to the peptide [Gly-(Glu) 3-Gly(Glu) $2 \mathrm{Y}$ ] that cause carboxy terminus of tyrosylated alpha-tubulin. It forms the ends of the amino acids (8 last

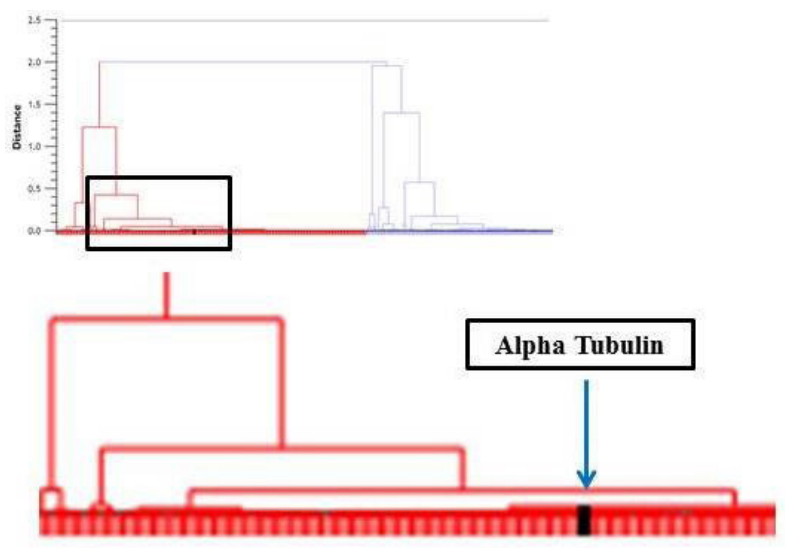

Figure 4. The alpha-tubulin position has shown in the diagram cluster.

amino acids) in alpha-tubulin. ${ }^{46,47}$ The carboxy terminus of proteins structure, modifications peptide are essential for tubulin function. ${ }^{48}$

Alpha-tubulin can also be separated and identified by electrophoresis (IEF and SDS-PAGE) and spectroscopy (MALDI-TOF-TOF). The resulting examined by software, protein database, and tubulin isotype specific tryptic peptides identified. It is such important human tubulin in different isotype include $\alpha_{3}, \alpha_{4}, \alpha_{6}, \alpha_{8}, K_{\alpha 1}$, and $\mathrm{b}_{\alpha 1}$. In all isotopes, post-translational modifications might create. $\alpha_{4}$ tubulin was in the brain. ${ }^{12,49}$ Alpha-tubulin isotype has a tyrosine or phenylalanine residue, which encoded at the end, but not exclusive. Researchers have shown that tyrosine accounts for a significant percentage of $\alpha_{4}$ tubulin, That is the reason functional $\alpha_{4}$ tubulin tyrosine ligase. The importance of the differences in tubulin can contribute to the biological recognition of the cytoskeleton system and the ways of rapid diagnosis and treatment of cancer. ${ }^{12,20,50,51}$ Tubulin was tyrosinatation and acetylation $\left(\right.$ lys $\left._{40}\right)$, was lower them the level of detection. Researchers have been investigating the correction of tubulin and post-transplantation in gliomas (astrocytoma and oligodendroglioma) and various types of cancer. ${ }^{49}$

We have shown changes in expression of proteins by clustering of alpha-tubulin related to oligodendroglioma; All the spots divided into 2 main clusters, Increase and

Table 2. Alpha-Tubulin Protein Matching the Same Set of Peptides By Databank Searching

\begin{tabular}{|c|c|c|c|c|c|}
\hline & Tubulin Alpha & Mass & Score & Matches & Sequences \\
\hline gi14389309 & $1 \mathrm{C}$ chain & 50548 & 801 & $8(8)$ & $8(8)$ \\
\hline gi3474335 & $1 \mathrm{~B}$ chain & 50804 & 801 & $8(8)$ & $8(8)$ \\
\hline gi62897609 & 6 Variant & 50476 & 801 & $8(8)$ & $8(8)$ \\
\hline gi193786502 & Unnamed & 46725 & 801 & $8(8)$ & $8(8)$ \\
\hline gi193787715 & Unnamed & 46825 & 801 & $8(8)$ & $8(8)$ \\
\hline gi296211572 & $1 \mathrm{~B}$ chain isoform 2 & 46797 & 801 & $8(8)$ & $8(8)$ \\
\hline gi221039556 & Unnamed & 58636 & 799 & $8(8)$ & $8(8)$ \\
\hline gi6755901 & 1A chain & 50788 & 789 & $8(8)$ & $8(8)$ \\
\hline gi73996547 & 1 isoform 9 & 46781 & 789 & $8(8)$ & $8(8)$ \\
\hline
\end{tabular}


Table 3. The $\mathrm{MW}$ and $\mathrm{pH}_{\mathrm{i}}$ of Each of the Tumors (Oligodendroglioma III) Compared to Control Independently

\begin{tabular}{|c|c|c|c|c|c|c|c|}
\hline & \multirow{2}{*}{ Tumor } & \multirow{2}{*}{ Grade } & \multirow{2}{*}{ Sex } & \multirow{2}{*}{ Age } & \multicolumn{3}{|c|}{ Alpha-Tubulin } \\
\hline & & & & & $P<0.05$ & MW & PI \\
\hline Case 1 & Oligodendroglioma & III & Woman & 51 & $5.873 \mathrm{e}-008$ & 51112 & 6 \\
\hline Case 2 & Oligodendroglioma & III & Man & 53 & $5.610 \mathrm{e}-006$ & 52603 & 5.76 \\
\hline Case 3 & Oligodendroglioma & III & Man & 42 & $3.258 \mathrm{e}-008$ & 48994 & 5.99 \\
\hline Case 4 & Oligodendroglioma & III & Man & 59 & $1.908 \mathrm{e}-005$ & 51393 & 6.11 \\
\hline Case 5 & Oligodendroglioma & III & Woman & 58 & $7.654 \mathrm{e}-008$ & 51507 & 5.98 \\
\hline Case 6 & Oligodendroglioma & III & Woman & 38 & $5.631 \mathrm{e}-005$ & 53006 & 6.12 \\
\hline Case 7 & Oligodendroglioma & III & Man & 66 & $2.658 \mathrm{e}-007$ & 49110 & 6.32 \\
\hline Case 8 & Oligodendroglioma & III & Man & 55 & $6.329 \mathrm{e}-006$ & 48707 & 5.72 \\
\hline
\end{tabular}

Table 4. Statistical Analysis of Molecular Weight and Isoelectric $\mathrm{pH}$ for Alpha-Tubulin

\begin{tabular}{lccccccccc}
\hline & Valid & Missing & Mean & Median & Error Of Mean & Variance & Min & Max & Rande \\
\hline PI & 8 & 0 & 6 & 6 & 0.182 & 0.033 & 5.72 & 6.32 & 0.6 \\
MW & 8 & 0 & 50804 & 51252.5 & 1563.82 & 2445543 & 48707 & 53006 & 4299 \\
\hline
\end{tabular}

decrease expression, indicate that alpha tubulin placed in a cluster, which has an increased expression. This increase in alpha-tubulin expression is consistent with other studies, but with different overexpression. We have shown that alpha-tubulin as being a potential candidate for a biomarker of the diagnosis and prediction of oligodendroglioma tumors presented.

\section{Conflict of Interest Disclosure}

The authors declare that they have no conflict of interests.

\section{Ethical Statement}

All patients gave informed consent before participating in this study. The research was approved by the ethics committee of Islamic Azad University.

\section{Funding and Support}

The present study was sponsored by affiliation (number one) and all the authors of the paper.

\section{References}

1. Okamoto H, Li J, Glasker S, Vortmeyer AO, Jaffe H, Robison RA, et al. Proteomic comparison of oligodendrogliomas with and without $1 \mathrm{pLOH}$. Cancer Biol Ther. 2007;6(3):391-6. doi: 10.4161/cbt.6.3.3731.

2. Khaghani-Razi-Abad S, Hashemi M, Pooladi M, Entezari M, Kazemi E. Proteomics analysis of human oligodendroglioma proteome. Gene. 2015;569(1):77-82. doi: 10.1016/j. gene.2015.05.039.

3. Azarakhsh F, Changizi V, Pooladi M. Evaluation of the role of metabolites in the diagnosis of the brain tumors using the MRS of the intensified nuclear magnet. J Paramed Sci. 2015;6(2):72-8.

4. Deighton RF, McGregor R, Kemp J, McCulloch J, Whittle IR. Glioma pathophysiology: insights emerging from proteomics. Brain Pathol. 2010;20(4):691-703. doi: 10.1111/j.17503639.2010.00376.x.

5. Pooladi M, Khaghani-Razi-Abad S, Nazarian N, FirouziDalvand L, Hooshiyar M. Altered expression of Isocitrate Dehydrogenases 1 in astrocytoma (III and IV) and oligodendroglioma (III) brain tumors. Journal of Proteins and Proteomics. 2014; 5(1): 55-64.
6. Hashemi M, Pooladi M, Khaghani-Razi-Abad S. The investigation of changes in proteins expression (Apolipoprotein A1 and albumin) in malignant astrocytoma brain tumor. J Cancer Res Ther. 2014;10(1):107-11. doi: 10.4103/09731482.131413.

7. BrombergJE, van den Bent MJ. Oligodendrogliomas: molecular biology and treatment. Oncologist. 2009;14(2):155-63. doi: 10.1634/theoncologist.2008-0248.

8. Park CK, Kim JH, Moon MJ, Jung JH, Lim SY, Park SH, et al. Investigation of molecular factors associated with malignant transformation of oligodendroglioma by proteomic study of a single case of rapid tumor progression. J Cancer Res Clin Oncol. 2008;134(2):255-62. doi: 10.1007/s00432-007-02821 .

9. Grzendowski $M$, Wolter $M$, Riemenschneider $M$ J, Knobbe $\mathrm{CB}$, Schlegel $U$, Meyer HE, et al. Differential proteome analysis of human gliomas stratified for loss of heterozygosity on chromosomal arms $1 \mathrm{p}$ and 19q. Neuro Oncol. 2010;12(3):243-56. doi: 10.1093/neuonc/nop025.

10. Rostomily RC, Born DE, Beyer RP, Jin J, Alvord EC, Jr., Mikheev AM, et al. Quantitative proteomic analysis of oligodendrogliomas with and without $1 \mathrm{p} / 19 \mathrm{q}$ deletion. J Proteome Res. 2010;9(5):2610-8. doi: 10.1021/pr100054v.

11. Whittle IR, Short DM, Deighton RF, Kerr LE, Smith C, McCulloch J. Proteomic analysis of gliomas. Br J Neurosurg. 2007;21(6):576-82. doi: 10.1080/02688690701721691.

12. Verdier-Pinard P, Wang F, Angeletti RH, Horwitz SB, Orr GA. Tubulin proteomics in cancer. In: Fojo T, ed. The role of microtubules in cell biology, neurobiology, and oncology. Totowa, NJ: Humana Press; 2008:193-210.

13. Westermann S, Weber K. Post-translational modifications regulate microtubule function. Nat Rev Mol Cell Biol. 2003;4(12):938-47. doi: 10.1038/nrm1260.

14. Seeds NW, Maccioni RB. Proteins from morphologically differentiated neuroblastoma cells promote tubulin polymerization. J Cell Biol. 1978;76(2):547-55. doi: 10.1083/ jcb.76.2.547.

15. Fellous A, Francon J, Lennon AM, Nunez J. Microtubule assembly in vitro. Purification of assembly-promoting factors. Eur J Biochem. 1977;78(1):167-74.

16. Tseng CY, Mane JY, Winter P, Johnson L, Huzil T, Izbicka E, et al. Quantitative analysis of the effect of tubulin isotype expression on sensitivity of cancer cell lines to a set of 
novel colchicine derivatives. Mol Cancer. 2010;9:131. doi: 10.1186/1476-4598-9-131.

17. Derry WB, Wilson L, Khan IA, Luduena RF, Jordan MA. Taxol differentially modulates the dynamics of microtubules assembled from unfractionated and purified beta-tubulin isotypes. Biochemistry. 1997;36(12):3554-62. doi: 10.1021/ bi962724m

18. Staff NP, Podratz JL, Grassner L, Bader M, Paz J, Knight AM, et al. Bortezomib alters microtubule polymerization and axonal transport in rat dorsal root ganglion neurons. Neurotoxicology. 2013;39:124-31. doi: 10.1016/j.neuro.2013.09.001.

19. Barlan K, Lu W, Gelfand VI. The microtubule-binding protein ensconsin is an essential cofactor of kinesin-1. Curr Biol. 2013;23(4):317-22. doi: 10.1016/j.cub.2013.01.008.

20. Calligaris D, Verdier-Pinard P, Devred F, Villard C, Braguer D, Lafitte D. Microtubule targeting agents: from biophysics to proteomics. Cell Mol Life Sci. 2010;67(7):1089-104. doi: 10.1007/s00018-009-0245-6.

21. Piperno G, Fuller MT. Monoclonal antibodies specific for an acetylated form of alpha-tubulin recognize the antigen in cilia and flagella from a variety of organisms. J Cell Biol. 1985;101(6):2085-94. doi: 10.1083/jcb.101.6.2085.

22. Berges R, Balzeau J, Takahashi M, Prevost C, Eyer J. Structurefunction analysis of the glioma targeting NFL-TBS.40-63 peptide corresponding to the tubulin-binding site on the light neurofilament subunit. PLoS One. 2012;7(11):e49436. doi: 10.1371/journal.pone.0049436.

23. Efrat A, Hoffmann F, Kriegel K, Schultz C, Wenk C. Geometric algorithms for the analysis of 2D-electrophoresis gels. J Comput Biol. 2002;9(2):299-315. doi: 10.1089/10665270252935476.

24. Kozuka-Hata H, Nasu-Nishimura Y, Koyama-Nasu R, AoKondo H, Tsumoto K, Akiyama T, et al. Phosphoproteome of human glioblastoma initiating cells reveals novel signaling regulators encoded by the transcriptome. PLoS One. 2012;7(8):e43398. doi: 10.1371/journal.pone.0043398.

25. Pooladi M, Rezaei-Tavirani M, Hashemi M, Hesami-Tackallou S, Khaghani-Razi-Abad S, Firouzi-Dalvand L, et al. Altered Expression of Epidermal Growth Factor Receptor (EGFR) in Glioma. Biomacromolecular Journal. 2015;1(1):122-9.

26. Ahrens $\mathrm{CH}$, Brunner $\mathrm{E}$, Qeli E, Basler $\mathrm{K}$, Aebersold R. Generating and navigating proteome maps using mass spectrometry. Nat Rev Mol Cell Biol. 2010;11(11):789-801. doi: 10.1038/nrm2973.

27. Barbosa EB, Vidotto A, Polachini GM, Henrique T, Marqui AB, Tajara EH. Proteomics: methodologies and applications to the study of human diseases. Rev Assoc Med Bras (1992). 2012;58(3):366-75.

28. Honda K, Ono M, Shitashige M, Masuda M, Kamita M, Miura $\mathrm{N}$, et al. Proteomic approaches to the discovery of cancer biomarkers for early detection and personalized medicine. Jpn J Clin Oncol. 2013;43(2):103-9. doi: 10.1093/jjco/hys200.

29. Aebersold R, Anderson L, Caprioli R, Druker B, Hartwell L, Smith R. Perspective: a program to improve protein biomarker discovery for cancer. J Proteome Res. 2005;4(4):1104-9. doi: 10.1021/pr050027n.

30. Koshel BM, Wirth MJ. Trajectory of isoelectric focusing from gels to capillaries to immobilized gradients in capillaries. Proteomics. 2012;12(19-20):2918-26. doi: 10.1002/ pmic.201200213.

31. Mitchell P. Proteomics retrenches. Nat Biotechnol. 2010;28(7):665-70. doi: 10.1038/nbt0710-665.

32. Farahtaj F, Zandi F, Khalaj V, Biglari P, Fayaz A, Vaziri B. Proteomics analysis of human brain tissue infected by street rabies virus. Mol Biol Rep. 2013;40(11):6443-50. doi: 10.1007/s11033-013-2759-0.

33. Pooladi M, Khaghani-Razi-Abad S, Hashemi M. Proteomics analysis of human brain glial cell proteome by 2D gel. Indian J Cancer. 2014;51(2):159-62. doi: 10.4103/0019509x.138271.

34. Maurya Bharati D, Pawar Shweta V, Chate Priya B, Kayarkar Namita A, Durgude Suvarna G, Amol B, et al. Proteomics: Emerging analytical techniques. Int J Genet. 2009;1(2):17-24. doi: 10.9735/0975-2862.1.2.17-24.

35. Weiss W, Gorg A. High-resolution two-dimensional electrophoresis. Methods Mol Biol. 2009;564:13-32. doi: 10.1007/978-1-60761-157-8_2.

36. Chaurand P, Schwartz SA, Caprioli RM. Assessing protein patterns in disease using imaging mass spectrometry. J Proteome Res. 2004;3(2):245-52.

37. Jensen ON. Modification-specific proteomics: characterization of post-translational modifications by mass spectrometry. Curr Opin Chem Biol. 2004;8(1):33-41. doi: 10.1016/j. cbpa.2003.12.009.

38. Erlandsson A, Brannvall K, Gustafsdottir S, Westermark B, Forsberg-Nilsson K. Autocrine/paracrine platelet-derived growth factor regulates proliferation of neural progenitor cells. Cancer Res. 2006;66(16):8042-8. doi: 10.1158/00085472.can-06-0900.

39. Hammond JW, Cai D, Verhey KJ. Tubulin modifications and their cellular functions. Curr Opin Cell Biol. 2008;20(1):71-6. doi: 10.1016/j.ceb.2007.11.010.

40. Li G, Jiang $H$, Chang $M$, Xie H, Hu L. HDAC6 alphatubulin deacetylase: a potential therapeutic target in neurodegenerative diseases. J Neurol Sci. 2011;304(1-2):1-8. doi: 10.1016/j.jns.2011.02.017.

41. Kline-Smith SL, Walczak CE. Mitotic spindle assembly and chromosome segregation: refocusing on microtubule dynamics. Mol Cell. 2004;15(3):317-27. doi: 10.1016/j. molcel.2004.07.012.

42. Nogales E, Wang HW. Structural intermediates in microtubule assembly and disassembly: how and why? Curr Opin Cell Biol. 2006;18(2):179-84. doi: 10.1016/j.ceb.2006.02.009.

43. Berges R, Balzeau J, Peterson AC, Eyer J. A tubulin binding peptide targets glioma cells disrupting their microtubules, blocking migration, and inducing apoptosis. Mol Ther. 2012;20(7):1367-77. doi: 10.1038/mt.2012.45.

44. Chen J, Serizawa T, Komiyama M. Binding analysis of peptides that recognize preferentially cis-azobenzene groups of synthetic polymers. J Pept Sci. 2011;17(2):163-8. doi: 10.1002/psc. 1299.

45. Guerrini R, Salvadori S, Rizzi A, Regoli D, Calo G. Neurobiology, pharmacology, and medicinal chemistry of neuropeptide S and its receptor. Med Res Rev. 2010;30(5):75177. doi: 10.1002/med.20180.

46. Verdier-Pinard P, Pasquier E, Xiao H, Burd B, Villard C, Lafitte D, et al. Tubulin proteomics: towards breaking the code. Anal Biochem. 2009;384(2):197-206. doi: 10.1016/j. ab.2008.09.020.

47. Wehland J, Willingham MC, Sandoval IV. A rat monoclonal antibody reacting specifically with the tyrosylated form of alpha-tubulin. I. Biochemical characterization, effects on microtubule polymerization in vitro, and microtubule polymerization and organization in vivo. J Cell Biol. 1983;97(5 Pt 1):1467-75. doi: 10.1083/jcb.97.5.1467.

48. Kumar N, Flavin M. Preferential action of a brain detyrosinolating carboxypeptidase on polymerized tubulin. J Biol Chem. 1981;256(14):7678-86.

49. Nakagawa U, Suzuki D, Ishikawa M, Sato H, Kamemura K, Imamura A. Acetylation of alpha-tubulin on Lys40 is a widespread post-translational modification in angiosperms. Biosci Biotechnol Biochem. 2013;77(7):1602-5. doi: 10.1271/bbb.130261. 